\title{
Synthesis of naphthothiophene derivatives through polar Diels-Alder reactions employing 5-nitrobenzothiophene as electrophile. Microwave irradiation vs classical thermal conditions
}

\author{
Claudia Della Rosa*, Pedro Mancini, Maria N. Kneeteman \\ Área Química Orgánica- Departamento de Química- Facultad de Ingeniería Química, Universidad \\ Nacional del Litoral. Santiago del Estero 2829. (3000) Santa Fe, Argentina. \\ FAX: +54-342-4571162.*e-mail: cdellaro@fiq.unl.edu.ar
}

\begin{abstract}
Herein we report a simple, economical and efficient one-step procedure to synthesize the naphtho[2,1-b]thiophene ring system in good to excellent yield through the polar Diels-Alder reactions of 5-nitro-3-acetylbenzothiophene and dienes of different nucleophilicity. In thermal conditions the reactions were developed in molecular solvents; moreover the reaction system was exposed to microwave irradiation as a complement of reaction conditions.
\end{abstract}

Keywords: Nitrobenzothiophene, electrophile, Diels-Alder

\section{Introduction}

Naphthothiophene has been reported as a promising p-type semiconductor. The development of high-performance $n$-type semiconductors is highly desirable. ${ }^{1}$

On the other hand, in the hierarchy of carbon-carbon bond constructions, the DielsAlder (DA) reaction has attained a preminent position. Its potential in heterocyclic chemistry synthesis is very well known. This process is in one step inter or intramolecular from aspects diene and dienophile bearin an almost unlimited number of variants. ${ }^{2,3}$

Recently we have reported a simple scheme to synthesize the dibenzothiophene ring system in good yield through the DA reaction of 2- and 3-nitrobenzothiophenes and different dienes. ${ }^{4}$

Herein we report a simple, economical and efficient one-step procedure to synthesize the naphtho[2,1-b]thiophene ring system in good yield through the polar DA reactions of 5-nitrobenzothiophene and electron-rich (ER) dienes. A very strong EW group, such as nitro group, push the nucleophilic character of these heterocyclic compounds and owing to this substituent is easily extruded under thermal conditions make this reaction sequence a simple method of organic compound's families with heteroatom rings preparation.

\section{Results and Discussion}

The study of P-DA reactions was carried out employing 5-nitro-3-acetylbenzothiophene 1a as electrophilic dienophile, whereas 1-methoxy-3-trimethylsilyloxy-1,3-butadiene 2, 1- trimethylsilyloxy-1,3-butadiene 3 and isoprene $\mathbf{4}$ were chosen as ER diene partners (Figure 1). The selection of dienes took into account the type of substitution present in their structures and the relative nucleophilicity.

5-nitro-3-acetylbenzothiophenes 1a were prepared by acylation and nitration of benzothiophene, and subsequent chromatographic separation. 


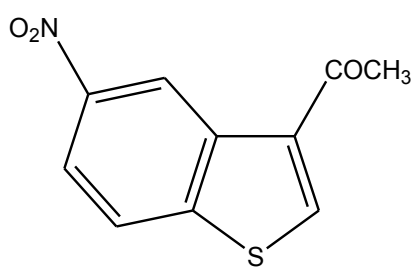

$1 \mathbf{a}$

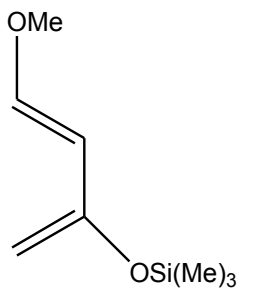

2

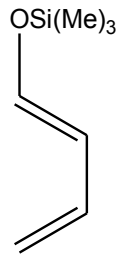

3

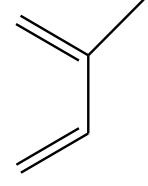

4

Figure 1

When 5-nitro-3-acetylbenzothiophene 1a reacted with Danishefsky's diene $\mathbf{2}$ in a sealed ampoule at $150^{\circ} \mathrm{C}$ and $120^{\circ} \mathrm{C}$ for $72 \mathrm{~h}$ using benzene as solvent the reaction proceeded to produce hidroxylated naphthothiophene $\mathbf{5}$ with acceptable yield and complete regioselectivity (Scheme 1, Table 1). These results indicate a properly substituted benzothiophene functions as a normal dienophile with an activated 1,3-butadiene.

Exposure of 1a to 1-trimethylsilyloxy-1,3-butadiene $3\left(150^{\circ} \mathrm{C}\right.$ and $120^{\circ} \mathrm{C}, 72 \mathrm{~h}, \mathrm{Bz}$ anh $)$ afforded naphthothiophene 6 with reasonable yield (53\% and 50\%). When 1a was then heated with less reactive isoprene $4\left(150^{\circ} \mathrm{C}\right.$ and $120^{\circ} \mathrm{C}, 72 \mathrm{~h}, \mathrm{Bz}$ anh), it gave pyrrolylbenzothiophene 7 in low yield formed by an assumed hetero cycloaddition followed by thermal rearrangement and isomeric naphthothiophenes $\mathbf{8 a}$ and $\mathbf{8 b}$ (Scheme 1, Table $1)^{5}$<smiles>CC(=O)c1csc2ccc3ccc(O)cc3c12</smiles><smiles>CC(=O)c1csc2ccc([N+](=O)[O-])cc12</smiles>

$1 \mathrm{a}$

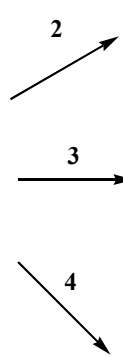<smiles>CC(=O)c1csc2ccc3ccccc3c12</smiles><smiles>CC(=O)c1csc2ccc(-n3ccc(C)c3)cc12</smiles>

Scheme 1

Considering that microwave irradiation (MW) has been used to enhance organic reactions, we realized some experiences in this P-DA reactions using molecular solvent (benzene) and solvent-free conditions. 
With microwave irradiation $\left(150^{\circ} \mathrm{C}\right.$ and $\left.180^{\circ} \mathrm{C}, 60 \mathrm{~min}\right)$ and benzene as reaction media was chosen, 1a react with 1-methoxy-3-trimethylsilyloxy-1,3-butadiene $\mathbf{2}$ afforded $\mathbf{5}$. The reactions of $\mathbf{1 a}$ with diene $\mathbf{3}$ in similar conditions produced naphthothiophene $\mathbf{6}$ in reasonable yield (entries 1,2,5,6 Table 2).

On the other hand, when 1a react with isoprene and MW irradiation using benzene as solvent product 7, 8a and $\mathbf{8 b}$ were obtained (entries 9,10; Table 2). These results are coincident with those previously obtained. ${ }^{6}$

Diels-Alder cycloaddition of 1a with Danishefsky's diene under microwave irradiation in solvent-free condition $\left(180^{\circ} \mathrm{C}\right.$ and $\left.150^{\circ} \mathrm{C}\right)$ gave 5 with very good yield (entries 3 and 4 , Table 2). On the other hand, when 3 reacted with 1a under microwave irradiation in solvent-free condition afforded naphthothiophene 6 (entries 7,8; Table 2) after elimination of the nitro group and in situ aromatization.

Finally, treatment of $\mathbf{1 a}$ with isoprene $\mathbf{8 a}, \mathbf{8 b}$ and 7 are obtained when microwave irradiation in solvent-free condition are used (entries 11, 12; Table2).

Table 1. Thermal reactions of nitrobenzothiophenes with dienes

of different reactivity

\begin{tabular}{|c|c|c|c|c|}
\hline Entry & Dienoph. & Diene & Conditions. $^{\mathrm{a}}$ & Product, yield ${ }^{b}$ \\
\hline 1 & $1 \mathrm{a}$ & 2,2 eq. & $150^{\circ} \mathrm{C}$ & $5,55 \%$ \\
\hline 2 & & & $120^{\circ} \mathrm{C}$ & $5,52 \%$ \\
\hline 3 & & 3,2 eq. & $150^{\circ} \mathrm{C}$ & $6,53 \%$ \\
\hline 4 & & & $120^{\circ} \mathrm{C}$ & $6,50 \%$ \\
\hline 5 & & $4,12 \mathrm{eq}$ & $150^{\circ} \mathrm{C}$ & $7,10 \% ; \mathbf{8 a}, \mathbf{b}, 15 \%$ \\
\hline 6 & & & $120^{\circ} \mathrm{C}$ & $7,5 \% ; \mathbf{8 a}, \mathbf{b}, 12 \%$ \\
\hline
\end{tabular}

Table 2. Diels-Alder reactions of nitrobenzothiophenes with different dienes employing microwave irradiation.

\begin{tabular}{|c|c|c|c|c|}
\hline Entry & Dienoph. & Diene & Conditions $^{\mathrm{a}}$ & Product, yield $^{\mathrm{b}}$ \\
\hline 1 & $1 \mathrm{a}$ & 2,2 eq. & $180^{\circ} \mathrm{C}, \mathrm{Bz}$ anh. & $5,56 \%$ \\
\hline 2 & & & $150^{\circ} \mathrm{C}, \mathrm{Bz}$ anh. & $5,54 \%$ \\
\hline 3 & & & $180^{\circ} \mathrm{C}$, Solv. Free & $5,70 \%$ \\
\hline 4 & & & $150^{\circ} \mathrm{C}$, Solv. Free & $5,68 \%$ \\
\hline 5 & & 3,2 eq. & $180^{\circ} \mathrm{C}, \mathrm{Bz}$. anh. & $6,50 \%$ \\
\hline 6 & & & $150^{\circ} \mathrm{C}, \mathrm{Bz}$. anh. & $6,48 \%$ \\
\hline 7 & & & $180^{\circ} \mathrm{C}$, Solv. Free & $6,58 \%$ \\
\hline 8 & & & $150^{\circ} \mathrm{C}$, Solv. Free & $6,55 \%$ \\
\hline 9 & & $4,12 \mathrm{eq}$. & $180^{\circ} \mathrm{C}, \mathrm{Bz}$. anh. & $7,10 \% ; \mathbf{8 a}, \mathbf{b} ; 17 \%$ \\
\hline 10 & & & $150^{\circ} \mathrm{C}, \mathrm{Bz}$. anh. & $7,8 \% ; \mathbf{8 a}, \mathbf{b} ; 12 \%$ \\
\hline 11 & & & $180^{\circ} \mathrm{C}$, Solv. Free & $7,12 \% ; \mathbf{8 a}, \mathbf{b} ; 20 \%$ \\
\hline 12 & & & $150^{\circ} \mathrm{C}$, Solv. Free & $\mathbf{7 , 8 \%} ; \mathbf{8 a}, \mathbf{b} ; 18 \%$ \\
\hline
\end{tabular}

${ }^{\mathrm{b}}$ Based on consumed nitrobenzothiophene. 


\section{Conclusions}

The reactions between 5-nitro-3-acetylbenzothiopheno $\mathbf{1 a}$ and different dienes, developed in benzene as solvent to yield naphthothiophenes derivatives permit to conclude that a properly substituted benzothiophene functions as a normal dienophile with an activated 1,3-butadiene.

With microwave irradiation and benzene as reaction media, 1a react with $\mathbf{2 ,} \mathbf{3}$ and $\mathbf{4}$, respectively, to yield the same products than before. Reaction of dienes $\mathbf{2}$ and $\mathbf{3}$ with 5nitrobenzothiophenes 1a under microwave irradiation in solvent-free condition give good yields of the aromatic naphthothiophenes through elimination of the nitro group and subsequent aromatization.

The use of MW irradiation decreases the time of reaction for similar yields.

\section{Acknowledgments}

This research was supported by CAI+D 2011- 66/069 at Universidad Nacional del Litoral, Santa Fe, Argentina.

\section{References and notes}

1- Di Wu; Zhao Chen; Yufeng Zhang; Jing Zhang; Sheng Hua Liu; Jun Yin. J.Org. Chem. 2015, 80, 8443-8448.

2- For general rewiew, see: (a) W. Carruthers in Cycloaddition Reactions in Organic Snthesis, Pergamon Press, Oxford, UK, 1990; (b) F. Fringelli, A. Tatichi in The DielsAlder Reaction, J. Wiley \& Sons, Chichester, UK, 2002; (c) E.J. Corey, Angew. Chem. Int. Ed., 41, 1650-1667, 2002.

3- a) B. Biolatto, M. Kneeteman, P. Mancini, Tetrahedron Lett. 1999, 40, 3343; b) B. Biolatto, M. Kneeteman, E. Paredes, P.M.E. Mancini, J. Org. Chem. 2001, 66, 3906. c) C. Della Rosa, M.N. Kneeteman, P.M.E. Mancini, Tetrahedron Lett. 2007, 48, 1535.

a) C. Della Rosa, C. Ormachea, M.N. Kneeteman, C. Adam, P.M.E. Mancini. Tetrahedron Lett. 2011, 52, 6754. b) C.D. Della Rosa, C.M. Ormachea, A. S. Sonzogni, M. N. Kneeteman, L. R. Domingo, P. M. E. Mancini, Lett. In Org. Chem. 2012, 9, 691.

4- C.D. Della Rosa; P.M.E. Mancini; M.N. Kneeteman; A.F. López Baena; M. Suligoy;

L.R. Domingo. Journal of Molecular Structure, 2015, 1079, 47-53.

5- The temperature, the length of the reaction, and the diene/dienophile ratio were dependent on the starting material and are indicated in Table 1. An ampule containing a solution of $1.0 \mathrm{mmol}$ of the dienophile and the required amount of diene in $1 \mathrm{ml}$ of dry benzene was cooled in liquid nitrogen, sealed (under nitrogen atmosphere), and then heated with stir in a bath. After the reaction time was completed, it was cooled once more in liquid nitrogen and opened. The solution was evaporated and the residue purified by column chromatography on silica gel or alumina using hexane/ethyl acetate mixtures as eluent.

6- Microwave irradiation was performed in a Anton Parr Monowave 300, microwave reactor in standard closed vessels. The temperature, the length of the reaction, and the diene/dienophile ratio were dependent on the starting material and are indicated in Table 2. After the reaction time was completed, the solution was evaporated and the residue purified by column chromatography on silica gel or alumina using hexane/ethyl acetate mixtures as eluent. 